\title{
A Systematic Search and Technical Review of Online Information Pertaining to Medical Care for Patients with Disability
}

\author{
Katherine D. Goss, Michael Ioerger, Virginia Young, Reed M. Flanders, Margaret A. Turk \\ SUNY Upstate Medical University
}

PREPRINT

OSF Preprint: July 5, 2018

Author Note

Katherine D. Goss, B.S., Department of Physical Medicine \& Rehabilitation, SUNY Upstate Medical University, Syracuse, NY 13210, USA; Michael Ioerger, PhD, MPH, Department of Physical Medicine \& Rehabilitation, SUNY Upstate Medical University, Syracuse, NY 13210, USA; Virginia Young, MLS, Health Sciences Library, SUNY Upstate Medical University, Syracuse, NY 13210, USA; Reed M. Flanders, B.A., Department of Physical Medicine \& Rehabilitation, SUNY Upstate Medical University, Syracuse, NY 13210, USA; Margaret A. Turk, MD, Department of Physical Medicine \& Rehabilitation, SUNY Upstate Medical University, Syracuse, NY 13210, USA.

Correspondence concerning this article should be addressed to Katherine D. Goss, 310 Jacobsen Hall, Department of Physical Medicine \& Rehabilitation, SUNY Upstate Medical University, Syracuse, NY 13210; Phone: 315-464-1924; E-mail: gossk@upstate.edu.

\begin{abstract}
This study examines the utility of online searches and technical quality of the resulting sites and materials when searching for information related to medical care for patients with disability. Systematic searches were conducted on two popular search engines using six search phrases. Resources were coded to categorize result information, presenting organization, and technical quality (attributes which allow for critical evaluation of source material). Only $8.9 \%$ of returned results included educational information about providing medical care for people with disability. Analyzed resources were most often from non-profit organizations $(31.7 \%)$ in website format $(60.2 \%)$. The composite technical quality score for all included resources had a median and mode of three on a scale of six technical attributes. This study provides a descriptive and technical assessment of the results from using popular search engines to locate information related to providing medical care for patients with disability. Less than $10 \%$ of the search results returned educational information, and many of these resources lacked technical information needed to allow viewers to critically evaluate the material. Sources within the first 100 search results of each search phrase and search engine pairing had a slightly higher inclusion rate at $15.6 \%$, compared to an overall inclusion rate of $13.3 \%$. Future work should investigate the quality and content of the information provided via online resources related to medical care for patients with disability, and potentially develop a collection of high-quality resources for health care professionals, patients, family members, and other professionals and organizations.
\end{abstract}




\section{A Systematic Search and Technical Review of Online Information Pertaining to Medical Care for Patients with Disability}

Little is known about the resources viewers encounter online that are related to medical care for patients with various disabilities. Many medical providers' lack of knowledge, skills, and formal training on caring for patients with disability is sometimes felt among populations with disability (Iezzoni \& Long-Bellil, 2012; Independence Care System, 2016; World Health Organization, 2011). The public more routinely turns to the internet to seek health care information (Fox \& Duggan, 2013), and this is likely true for people with disability and their families. Medical providers themselves have also demonstrated the use of online information to inform clinical care (Doney, Barlow, \& West, 2005; Schilling, Steiner, Lundahl, \& Anderson, 2005), and due to a lack of formal training, this practice is likely to carry into medical care for patients with disability. Thus, the information available online has the potential to guide disability-related clinical decisions and interactions. Despite the obvious easy access to medical and health care information, there is little knowledge about the quality and availability of disability-related health information that will meet the variety and depth of needs of patients with disability and their families (Alsem et al., 2014).

\section{The Internet as a Source of Information Pertaining to Medical Care}

Internet access in the United States continues to expand, increasing availability of the internet as a source of information. Use of the internet extends to matters related to health and medical care, with $70-72 \%$ of surveyed internet users reporting having looked online for some health information within the past year (Fox \& Duggan, 2013; Prestin, Vieux, \& Chou, 2015). With such widespread use of online health information, it is understandable that patients, their family members, as well as health care providers, are using internet sources to inform clinical 
health interactions (Alsem et al., 2017; Doney et al., 2005; Schilling et al., 2005). Given the lack of formal training provided to medical providers pertaining to caring for patients with disability (Iezzoni \& Long-Bellil, 2012; Independence Care System, 2016; World Health Organization, 2011), and the potentially unmet information needs, it is especially likely that information available online related to medical care for patients with disability is being sought.

\section{Technical Quality of Information Available Online}

While increased health information available online serves as a valuable tool for communication and dissemination of information, the internet provides endless opportunities for incomplete, biased, and misleading information (Silberg, 1997). Silberg et. al. proposed, in a 1997 Journal of the American Medical Association (JAMA) editorial, a set of core standards upon which to evaluate online sources of health information. These core standards have since been utilized and adapted to determine technical quality of online resources in several similar studies (Bonnar-Kidd, K., Black, D., Mattson, M., Coster, 2009; Jetha, Faulkner, Gorczynski, Arbour-Nicitopoulos, \& Martin Ginis, 2011; Shaw, Mallory, Arkell, \& Martin Ginis, 2017). These technical attributes (e.g. contact information, author name, reference listing) allow for critical evaluation of presented information by source viewers. Continued adaptation of the original JAMA standards is predicted in the future, as a diverse and ever-evolving collection of material is in need of a set of quality standards which can adapt and grow as well (Kim, Eng, Deering, \& Maxfield, 1999).

\section{Current Study}

This systematic search and technical review provides an initial survey of the information viewers may encounter when using online search engines to locate information related to medical care for patients with disability. This review examines the utility of internet search 
engines, identifies common sources of online information related to medical care for patients with disability, and assesses the presence of technical attributes which allow for critical evaluation of the information. The goal of this search and technical review is to provide an overview of the information available online for patients with disability, their families, and health care professionals.

\section{Methods}

Exhaustive systematic searches were performed using six different search phrases with two commonly utilized search engines (i.e., Google \& Yahoo). Two reviewers independently assessed each search result to include sources that provided information related to medical care for patients with disability. Then, each source was reviewed by two independent reviewers to code source attributes and evaluate technical quality.

\section{Protocol and Information Sources}

Six search phrases (see Table 1) were used verbatim to run searches on the two most commonly utilized search engines, Google and Yahoo (Purcell, Brenner, \& Rainie, 2012). The topic area of disability presents unique challenges in electronic searching, as search terms may have synonyms that are general in nature (hence false results) or searches neglect to identify targeted content that contains diagnosis-specific terminology (Schaefer, 2015). In order to develop an effective search protocol, search phrases were developed in consultation with a university librarian (VY) with experience in systematic searches and reviews and content knowledge related to disability. The PRISMA guidelines (Moher, Liberati, Tetzlaff, \& Altman, 2009) were used to guide the protocol development and reporting.

\section{Search}

One author (KDG) conducted each of the searches by accessing the main page of each 
search engine site, without signing-in to a personal profile. The link for each search result was added to a database one at a time, until the search engine reported that no additional results remained. Each search was completed without exiting the browser, to ensure that all results available at the time of the search were captured. This process was repeated for each of the six search terms on both search engines.

\section{Eligibility}

To be eligible for review, returned search engine results needed to have a web link and be presented in English.

\section{Source Selection}

After the links from all twelve searches were collected, duplicates were eliminated, and each unique link was followed so that the site could be evaluated against the study's inclusion and exclusion criteria. As part of the duplicate removal process, results from each additional search phrase were compared to results from the searches already conducted, such that only unique links were carried through to the next phase of the project. Google searches were completed first, and only additional unique search results returned by Yahoo were carried through to the next phase of the project. Included sources were those that were available in English, open-access (were presented in full and did not require a log-in), provided health information (e.g. best practice recommendations, treatment guidelines, recommendations for patients in clinical settings, descriptive information for a specific condition), and provided information relevant to functional disability (see Table 2: Source inclusion Criteria). Sources that included information on health conditions that by definition or diagnosis present with a functional limitation were considered disability focused. 
Sources were excluded if their link was broken, if information presented was not relevant to both disability and health, or was focused on a topic outside of medical care for patients with disability. This involved excluding sources that provide information focused only on medical school curriculum changes, disability insurance benefits, legislation, or government policy, or sources that were advertisements or job postings. Sources presented in the form of empirical articles (e.g. journal articles, thesis papers, and dissertations), news articles, notifications of current events, organization policy documents, and books or book chapters were also excluded. The decision to exclude empirical articles was made because many of the articles were not openaccess (available in full without sign-in or payment). Inclusion of these articles would not have reflected the sources available to all viewers.

To ensure the accuracy and appropriateness of inclusion and exclusion criteria, the criteria were pilot tested with the first 150 eligible returned search results. Two reviewers (KDG and MI) independently evaluated each of the eligible search results, and then reconciled their inclusion and exclusion decisions through a consensus method. A third reviewer (MAT) was available to make the include/exclude decision in any instances where consensus could not be reached. After the initial pilot testing and refinement of the inclusion and exclusion criteria, the search and inclusion decision process was repeated from the beginning. Figure 1 provides the exclusion flow chart for the full study selection process.

\section{Data Collection Process}

To assess the utility of the data collection tool, all included sources among the first 150 identified during the pilot study were coded for their content and technical quality. This coding was completed independently by two reviewers (KDG and NN), and then reconciled using a consensus method for each data point. A third reviewer (MAT) was available to make a final 
decision in any instances where consensus could not be reached. After the initial pilot testing and refinement of the data collection tool, the search and coding process started again from the beginning.

After inclusion/exclusion decisions were made for all of the links collected for the full study, a randomized selection of sources was provided to three separate reviewers (KDG, MI, and RMF). Each result was independently reviewed by at least two reviewers. Twenty sources were reviewed by all three reviewers. To ensure consistency, all three reviewers assessed twenty sources, and completed a reconciliation process, again with an additional reviewer (MAT) available to make a final decision in any instances where consensus could not be reached.

\section{Data Items}

Two different types of variables (i.e., Source Descriptors and Source Technical Quality) were analyzed for each included source. Analysis decisions were made from the information available on the page returned by following the web link.

Source Descriptor Variables: These variables include: title, presenting organization, organization classification (i.e., government, professional, non-profit/community based, for profit, university based, other), and method of information presentation (i.e., Website, PDF, slideshow/powerpoint, other).

Source Technical Quality Variables: the presence of seven technical attributes was assessed. These technical attributes were adapted from standards of critical evaluation for online resources originally published in the Journal of the American Medical Association (JAMA) (Silberg, 1997), and since adapted by several reviews (Bonnar-Kidd, K., Black, D., Mattson, M., Coster, 2009; Jetha et al., 2011; Shaw et al., 2017). Three attributes utilized in this study were taken directly from the original JAMA standards (i.e. Authorship, attribution (references), and 
currency (publication year), and two others were adapted (i.e. Disclosure of partners and Funding disclosure) from the original JAMA standard identified as "disclosure". The original disclosure standard was separated with influence from the other adapted review articles, to define separate topics of partner disclosure (e.g. identification of collaborative or endorsing agencies) and funding disclosure (identification of funding source). A seventh technical attribute, the presence of outside resources, was added and adapted from another review of quality of online education materials (Griffin, McKenna, \& Worrall, 2004).

For this review, a composite technical quality score (TQS) for each source was calculated to produce a summary measure of technical quality. Attributes included in this composite score include: availability of outside resources, authorship, provision of contact information, listing of references, listing of publication year, and disclosure of partners (for definitions see Table 3). These variables were coded dichotomously $(1=$ present, $0=$ absent $)$ based on the listing of each attribute, with the highest TQS being 6 points. Funding disclosure was not included in calculations of a composite technical quality score, as not all sources could be expected to provide this information (e.g. self-funded government organizations).

\section{Results}

\section{Identifying Relevant Sources}

A total of 3,866 results were returned through use of all six search phrases on both search engines. After duplicates were removed, 2,581 unique results were evaluated based on the exclusion/inclusion criteria. A total of 344 sources (13.3\% of all unique sources, $8.9 \%$ of all search results) met the criteria and were included in the analyses (see Table 4 for a breakdown of results by search phrase and search engine; see Supplemental Online Material - Appendix A for all included sources). Of the excluded sources, 552 (24.7\%) were excluded because their main 
purpose was promotion of services, 313 sources (14\%) were excluded due to their status as empirical articles (e.g. journal articles, thesis papers, dissertations), and 293 (13.1\%) sources were excluded because they were not considered disability focused (see Figure 1 for counts of all reasons for exclusion).

An additional analysis of the utility of the first 100 search results returned by each search phrase was conducted. A total of 187 sources $(15.6 \%$ of all sources within the first 100 unique search results for each search phrase and search engine pairing) met the criteria and were included in the analyses. Overall, $54.4 \%$ of all included sources were among the first 100 search results of each search phrase and search engine pairing (187 included sources within first 100 results/344 total included sources). Compared to sources following the first 100 search results of each search phrase and search engine pairing, sources within the first 100 results were not significantly different in TQS $(t=0.027 ; p=0.979)$.

\section{Source Descriptors}

Non-profit organizations were responsible for the largest number of included sources $(31.7 \%, \mathrm{n}=109)$. Government organizations presented the second largest number of included sources $(22.1 \% ; n=76)$, followed by for-profit organizations $(19.5 \% ; n=67)$, as noted in Table 5. Additionally, the majority of all included sources $(60.2 \%, \mathrm{n}=207)$ used a webpage to present information to viewers. A little over one third of all included sources $(36.1 \%, \mathrm{n}=124)$ were presented in PDF format, while only $3.8 \%(n=13)$ were presented in slideshow format.

\section{Technical Quality}

Technical Quality Score (TQS) for all 344 included sources had both a median and mode of three out of six technical quality attributes. Sources presented by university-based organizations $(13.7 \%$ of total; $\mathrm{n}=47$ ) had the highest median and mode TQS (Median $=4$, Mode 
= 5; see Table 6). Additionally, information presented as a PDF had the highest median and mode TQS $($ Median $=4$, Mode $=4)$, compared to sources presented in either website $($ Median $=$ 3 , Mode $=3$ ) or slideshow format $($ Median $=3$, Mode $=2)$. Contact information was the most commonly fulfilled individual technical attribute, with $79.7 \%$ of all included sources $(n=274)$ providing some method to contact responsible parties. Outside resources were provided in $63.7 \%$ of all included sources $(n=219)$, with publication year being listed in $62.2 \%$ of all included sources ( $n=214$; see Table 7).

\section{Discussion}

Overall, this systematic search and technical review identifies common sources of online information related to medical care for patients with disability, evaluates the utility of utilizing internet search engines to locate this information, and assesses the presence of technical attributes which allow for its critical evaluation. It was found that less than $10 \%$ of results returned when searching for information related to medical care for patients with disability provided relevant information. Additionally, among the first 100 search results from each search phrase and search engine pairing, only $15.4 \%$ of these results provided relevant information, representing only $54.5 \%$ of all included sources. Therefore, it can be challenging to find relevant sources of information among all of the returned search results. For the results that did provide relevant information, technical quality was low, with the majority of sources failing to provide pieces of information necessary for critical evaluation of source content. While differences among presenting organizations did exist in terms of technical quality, only $4.1 \%$ of all sources presented all six analyzed technical attributes. Thus, the findings of this study suggests that there are barriers to both seeking and trusting online information pertaining to medical care for patients with disability. This raises questions about the overall utility of online searches for 
information on medical care for patients with disability, given the sparsity of relevant results and lack of technical attributes available to assess the information that is found.

\section{Sparsity of Relevant Results}

Only a small number of results provided information relevant to medical care for people with disability, despite the use of search phrases tailored to return these sources. The large number of results providing irrelevant information highlights the difficulty associated with looking for disability information online. While slightly higher inclusion rates were observed among the first 100 search results for each search phrase, viewers who utilize only a small section of initial search results are missing almost half of the available relevant information. Health care providers are expected to gain information literacy and searching skills in medical, nursing, and health professions education, however this rarely becomes an area of expertise (Schuers et al., 2016; Younger, 2010). As noted above, the topic area of disability can be defined and described with a great deal of variation, and therefore, it is particularly difficult to determine accurate yet not overly restrictive search terms (Schaefer, 2015; Walsh, Peterson, \& Judkins, 2014). Thus, it might be challenging for all population groups to find information related to caring for patients with disability using popular search engines. Viewers may be left to rely on a small portion of information on which to base clinical interactions, decisions, and expectations. Additionally, the information these groups do find to meet their varying information needs (Alsem et al., 2014) may then be of low technical quality.

\section{Limited Identification of Technical Attributes}

The general lack of listing of technical attributes by included sources is concerning, due the potential negative impact of misleading or inaccurate information. Many of the resources possessed only half of the technical quality attributes, and thus fail to provide information 
necessary to promote critical evaluation of presented information by viewers. While the largest number of sources were produced by non-profit and government organizations, university-based organizations possessed the highest comparative TQS. This mismatch in technical quality and presenting organization is a demonstration of the generally unpredictable quality of resources on the internet in general, and calls for critical, thorough, and thoughtful evaluation of information presented online related to medical care for patients with disability.

Disclosure of partners was the least listed technical attribute included in calculation of the TQS. Transparency in the creation of all health information is crucial. Full disclosure related to the underpinnings of the resource information is needed for perspective on the presented content, as without this knowledge, it is not clear whether clinical expertise, personal opinion (either clinician or consumer), peer-reviewed publications, or combinations of these informed the content. A lack of disclosure of partnerships where partnerships existed would demonstrate a lack of honest and transparent reporting and decrease the extent to which provided information can be used to its full and intended extent by critical viewers. Alternatively, if a lack of disclosure of partnerships has been found among included sources due to a lack of collaboration in information development, questions are raised regarding biases leading the development of the information found. With the general push toward an interprofessional and collaborative approach to the delivery of health care services, benefits of collaborative development of health information should not be ignored.

The findings of this study in relation to a general lack of technical attributes, and the overall lack of specific technical attributes (e.g. disclosure of partners), should be understood and considered by professionals and others developing online health information. While the decision to model an assessment of technical quality using the original and adapted JAMA standards was 
made, authors are confidence that similar measurement tools would reach the same conclusion, especially since other measurement tools include several of the same concepts (e.g. accountability criteria identified by Griffin, et. al). In the future, tools utilized to assess technical quality should continue to be adapted and altered to fit the nature of analyzed sources, and the ever-changing landscape of information available online. As stated by Kim et. al. (1999): “Given the evolving state of the internet, it may be difficult or even inappropriate to develop a static tool or system for assessing health related web sites."

When technical attributes are not listed, viewers may unintentionally believe in the veracity of the information, not acknowledging the part content developers have had in production. Information developers who are aiming to provide useful and important information related to disability online thus have an obligation to present this information as seriously and transparently as possible. This includes providing source information, seeking and listing collaboration to ensure expert development of information, listing the currency of all recommendations and source information, and ensuring that viewers have all other pieces of information necessary to develop their own opinions on the credibility of the source. With this, information online will increasingly be able to help all viewers reach their information needs and correctly inform clinical interactions and decisions. The addition and inclusion of technical attributes will benefit all groups of viewers and developers alike.

With increasing use of the internet to find health information, low-quality and potentially inaccurate information can influence health care experiences in a negative way. While not all health care providers may utilize publicly available sources as a primary source of clinical information, the influence of internet sources on clinical interactions is unavoidable, due to use and accessibility of this information among patients, family members, and professionals and 
organizations. Therefore, our recommendations pertain not only to consumers of online information related to medical care for patients with disability, but to content developers of this information.

\section{Strengths \& Limitations}

This study has several strengths. This systematic search and technical review is the first, to the authors' knowledge, to focus on online resources providing information about medical care for patients with disability found through popular search engines. Additionally, the exhaustive nature of the search protocol captured a high-resolution snapshot of the landscape of available resources in this domain. The methodology of having two independent coders and a consensus review process contributes to the consistency and accuracy of study coding. Finally, each of the sources were evaluated to capture key information about the source and the technical quality of the resources. All of these attributes make this study a novel, methodologicallyrigorous, contribution to existing scientific literature

However, this study is not without limitations. The internet contains a vast amount of information that is highly varied in-terms of presentation and content, sometimes challenging project operational definitions. To address these challenges, pilot testing was used to verify the utility of the operational definitions, and two independent reviewers coded and reconciled each data point using a consensus method. The use of pilot testing procedures, the implementation of consensus reconciliation procedures with independent coders, and the large number of resources evaluated in this study all contribute to confidence in the overall pattern of results identified by this study.

It should also be noted that this study is limited by the use of six specific search phrases. While these search phrases were constructed by content experts with the help of a research 
librarian familiar with disability information, it is likely that the search terms utilized in this study failed to capture certain niches of information. However, the exhaustive nature of the searches run using popular search engines increase the confidence with which the results of this study can be seen as being representative of the resources available on the internet related to providing medical care to people with disability. It is important to note that this review was only meant to provide a descriptive assessment of the resources that are identified through similar internet searches and provide a coarse evaluation of their technical quality. The focus of this study was to evaluate ease in accessing appropriate information and assess technical attributes. To assess the accuracy of the content of the wide variety of information captured through this search process, multiple content experts would be needed to evaluate each source to provide expert opinion on the accuracy and quality of the information provided, which was beyond the scope of this study.

\section{Conclusions}

The overall utility of online search for information on medical care for patients with disability may be low, due to only a small number of relevant results and a sizable number of relevant results which are missed if not searching systematically. While inclusion rates were found to be slightly higher among the first 100 search results for each search phrase, viewers who look only at this small portion of initial results are missing almost half of the information available to them. Additionally, this study found that results returned by internet searches relevant to disability and health are of generally low technical quality. This means that it is not only difficult to locate sources of information related to medical care for patients with disability, but that it is also difficult to critically assess and apply this information. The diffuse nature of the resources located through this study suggests a more coordinated effort might be needed to 
develop a full-resolution collection of high-quality online sources of information related to medical care for patients of varying disability. 
Funding: This work was supported by the National Center on Birth Defects and Developmental Disabilities and the Centers for Disease Control and Prevention [Cooperative Agreement \#1U01DD001007-01].

Disclosures: The authors have no conflicts of interest to report. Acknowledgements: The authors would like to thank Nicolette Nunez, who was helpful in the development of project operational definitions. 


\section{Manuscript Charts and Figures}

Table 1. Utilized Search Phrases

1. Caring for patients with disability

2. How to care for patients with disability

3. Clinical care for patients with disability

4. Medical care for patients with disability

5. Health care providers and patients with disability

6. Clinical management of patients with disability 
Table 2. Source inclusion criteria

- Available in English

- Open-access (presented in full, does not require log-in)

- Provides health information

- Provides information relevant to functional disability

- Is not focused on disability benefits, medical school curriculum, legislation, or government policy

- Is not an advertisement or job posting

- Is not an empirical article (journal article, dissertation, etc.) 
Table 3. Variable Definitions- Source Technical Quality

A. Technical standards used to produce a composite technical quality score for each source:

i. Availability of outside resources: Are links provided to access related additional resources?

ii. Authorship: Is at least one specific author credited for the work?

iii. Provision of contact information: Is contact information (address, phone number, email address), or link to contact information, provided?

iv. Listing of references: Does the source credit the sources of its information?

v. Listing of publication year: Is a year of publication or content creation included in source information?

vi. Disclosure of partners: Do any organizations endorse the information provided, or, did multiple organizations collaborate in the production of the information?

B. Other technical standards evaluated, but not included in the production of a composite technical quality score:

$i$. Funding Disclosure: Does the source disclose any funding used in the production of the provided information? 
Table 4. Summary of search results by search phrase and search engine

\begin{tabular}{|c|c|c|c|c|c|c|c|c|c|c|c|}
\hline \multirow{2}{*}{$\begin{array}{c}\text { Search } \\
\#\end{array}$} & & & \multicolumn{3}{|c|}{ Google } & \multicolumn{3}{|c|}{ Yahoo } & \multicolumn{3}{|c|}{ Total } \\
\hline & \multicolumn{2}{|l|}{ Term Utilized } & Reviewed & Unique & Included & \multicolumn{2}{|c|}{ Reviewed Unique } & \multicolumn{3}{|c|}{ IncludedReviewed Unique } & Included \\
\hline 1 & $\begin{array}{l}\text { Caring for patients } \\
\text { with disability }\end{array}$ & $n$ & 465 & 434 & 84 & 258 & 177 & 20 & 723 & 611 & 104 \\
\hline & & $\begin{array}{l}\% \text { of } \\
\text { reviewed }\end{array}$ & - & 93.3 & 18.1 & - & 68.6 & 7.8 & - & 84.5 & 14.4 \\
\hline 2 & $\begin{array}{l}\text { How to care for } \\
\text { patients with }\end{array}$ & $n$ & 419 & 205 & 44 & 156 & 73 & 17 & 575 & 278 & 61 \\
\hline & disability & $\begin{array}{l}\% \text { of } \\
\text { reviewed }\end{array}$ & - & 48.9 & 10.5 & - & 46.8 & 10.9 & - & 48.3 & 10.6 \\
\hline 3 & $\begin{array}{l}\text { Clinical care for } \\
\text { patients with }\end{array}$ & $n$ & 319 & 270 & 19 & 165 & 114 & 16 & 484 & 384 & 35 \\
\hline & disability & $\begin{array}{l}\% \text { of } \\
\text { reviewed }\end{array}$ & - & 84.6 & 6.0 & - & 69.1 & 9.7 & - & 79.3 & 7.2 \\
\hline 4 & $\begin{array}{l}\text { Medical care for } \\
\text { patients with }\end{array}$ & $n$ & 406 & 281 & 31 & 524 & 201 & 17 & 930 & 482 & 48 \\
\hline & disability & $\begin{array}{l}\% \text { of } \\
\text { reviewed }\end{array}$ & - & 75.2 & 7.6 & - & 38.4 & 3.2 & - & 51.8 & 5.2 \\
\hline 5 & $\begin{array}{l}\text { Health care } \\
\text { providers and }\end{array}$ & $n$ & 364 & 234 & 38 & 309 & 202 & 15 & 673 & 436 & 53 \\
\hline & $\begin{array}{l}\text { patients with } \\
\text { disability }\end{array}$ & $\begin{array}{l}\% \text { of } \\
\text { reviewed }\end{array}$ & - & 64.3 & 10.4 & - & 65.4 & 4.9 & - & 64.8 & 7.9 \\
\hline 6 & $\begin{array}{c}\text { Clinical } \\
\text { management of }\end{array}$ & $n$ & 299 & 252 & 27 & 182 & 138 & 16 & 481 & 390 & 43 \\
\hline & $\begin{array}{l}\text { patients with } \\
\text { disability }\end{array}$ & $\begin{array}{l}\% \text { of } \\
\text { reviewed }\end{array}$ & - & 84.3 & 9.0 & - & 75.8 & 8.8 & - & 81.1 & 8.9 \\
\hline & Total & $n$ & 2272 & 1676 & 243 & 1594 & 905 & 101 & 3866 & 2581 & 344 \\
\hline & & $\begin{array}{l}\% \text { of } \\
\text { reviewed }\end{array}$ & - & 73.8 & 10.7 & - & 56.8 & 6.3 & - & 66.8 & 8.9 \\
\hline
\end{tabular}


Table 5. Classification of Presenting Organizations

\begin{tabular}{lcc}
\hline \multicolumn{1}{c}{$\begin{array}{c}\text { Organization } \\
\text { Classification }\end{array}$} & Number of Sources & Percent of Total Sources \\
\hline Non-Profit & 109 & 31.7 \\
Government & 76 & 22.1 \\
For-Profit & 67 & 19.5 \\
University Based & 47 & 13.7 \\
Professional & 35 & 10.2 \\
Other & 10 & 2.9 \\
Total & 344 & 100 \\
\hline
\end{tabular}


Table 6. Composite Technical Quality Score (TQS) Distribution by Organization Classification

\begin{tabular}{|c|c|c|c|c|c|c|c|c|c|c|}
\hline & & 0 & 1 & 2 & 3 & 4 & 5 & 6 & $\begin{array}{c}\text { Median } \\
T Q S\end{array}$ & $\begin{array}{c}\text { Mode } \\
T Q S\end{array}$ \\
\hline \multirow[t]{2}{*}{ All Organizations } & $\begin{array}{l}\text { Number of } \\
\text { Sources }\end{array}$ & 6 & 24 & 78 & 92 & 74 & 56 & 14 & 3 & 3 \\
\hline & $\%$ w/in $O C$ & 1.7 & 7.0 & 22.7 & 26.7 & 21.5 & 16.3 & 4.1 & & \\
\hline \multirow[t]{2}{*}{ Non-Profit } & $\begin{array}{l}\text { Number of } \\
\text { Sources }\end{array}$ & 0 & 6 & 33 & 31 & 21 & 14 & 4 & 3 & 2 \\
\hline & $\%$ w/in $O C$ & 0 & 5.5 & 30.3 & 28.4 & 19.3 & 12.8 & 3.7 & & \\
\hline \multirow[t]{2}{*}{ Government } & $\begin{array}{l}\text { Number of } \\
\text { Sources }\end{array}$ & 0 & 4 & 14 & 25 & 19 & 12 & 2 & 3 & 3 \\
\hline & $\%$ w/in $O C$ & 0 & 5.3 & 18.4 & 32.9 & 25.0 & 15.8 & 2.6 & & \\
\hline \multirow[t]{2}{*}{ For-Profit } & $\begin{array}{l}\text { Number of } \\
\text { Sources }\end{array}$ & 5 & 5 & 14 & 16 & 17 & 9 & 1 & 3 & 4 \\
\hline & $\%$ w/in $O C$ & 7.5 & 7.5 & 20.9 & 23.9 & 25.4 & 13.4 & 1.5 & & \\
\hline \multirow[t]{2}{*}{ University Based } & $\begin{array}{l}\text { Number of } \\
\text { Sources }\end{array}$ & 0 & 8 & 6 & 8 & 7 & 14 & 4 & 4 & 5 \\
\hline & $\%$ w/in $O C$ & 0 & 17.0 & 12.8 & 17.0 & 14.9 & 29.8 & 8.5 & & \\
\hline \multirow[t]{2}{*}{ Professional } & $\begin{array}{l}\text { Number of } \\
\text { Sources }\end{array}$ & 0 & 0 & 8 & 11 & 7 & 6 & 3 & 3 & 3 \\
\hline & $\%$ w/in $O C$ & 0 & 0 & 22.9 & 31.4 & 20.0 & 17.1 & 8.6 & & \\
\hline \multirow[t]{2}{*}{ Other } & $\begin{array}{l}\text { Number of } \\
\text { Sources }\end{array}$ & 1 & 1 & 3 & 1 & 3 & 1 & 0 & 2.5 & 2 \\
\hline & $\%$ w/in $O C$ & 10.0 & 10.0 & 30.0 & 10.0 & 30.0 & 1.0 & 0 & & \\
\hline
\end{tabular}


Table 7. Fulfillment of Individual Technical Standards by Organization Classification (OC)

\begin{tabular}{|c|c|c|c|c|c|c|c|c|}
\hline & & $O S$ & $A L$ & $C I$ & Ref & $P Y$ & $D o P$ & Fun.* \\
\hline \multirow[t]{2}{*}{$\begin{array}{c}\text { All } \\
\text { Organizations }\end{array}$} & $\begin{array}{l}\text { Number of } \\
\text { Sources }\end{array}$ & 219 & 170 & 274 & 184 & 214 & 58 & 42 \\
\hline & $\begin{array}{l}\% w / i n \\
O C\end{array}$ & 63.7 & 49.4 & 79.7 & 53.5 & 62.2 & 16.9 & 12.2 \\
\hline \multirow[t]{2}{*}{ Non-Profit } & $\begin{array}{l}\text { Number of } \\
\text { Sources }\end{array}$ & 67 & 52 & 86 & 56 & 59 & 13 & 17 \\
\hline & $\begin{array}{l}\% w / i n \\
O C\end{array}$ & 61.5 & 47.7 & 78.9 & 51.4 & 54.1 & 11.9 & 15.6 \\
\hline \multirow[t]{2}{*}{ Government } & $\begin{array}{l}\text { Number of } \\
\text { Sources }\end{array}$ & 48 & 40 & 61 & 48 & 50 & 16 & 10 \\
\hline & $\begin{array}{l}\% \text { w/in } \\
O C\end{array}$ & 63.2 & 52.6 & 80.3 & 63.2 & 65.8 & 21.1 & 13.2 \\
\hline \multirow[t]{2}{*}{ For-Profit } & $\begin{array}{l}\text { Number of } \\
\text { Sources }\end{array}$ & 43 & 33 & 51 & 26 & 47 & 10 & 0 \\
\hline & $\begin{array}{l}\% w / i n \\
O C\end{array}$ & 64.2 & 49.3 & 76.1 & 38.8 & 70.1 & 14.9 & 0 \\
\hline \multirow[t]{2}{*}{$\begin{array}{l}\text { University } \\
\text { Based }\end{array}$} & $\begin{array}{l}\text { Number of } \\
\text { Sources }\end{array}$ & 30 & 23 & 41 & 27 & 28 & 12 & 7 \\
\hline & $\begin{array}{l}\% w / i n \\
O C\end{array}$ & 63.8 & 48.9 & 87.2 & 57.4 & 59.5 & 25.5 & 14.9 \\
\hline \multirow[t]{2}{*}{ Professional } & $\begin{array}{l}\text { Number of } \\
\text { Sources }\end{array}$ & 24 & 17 & 28 & 18 & 24 & 3 & 6 \\
\hline & $\begin{array}{l}\% w / i n \\
O C\end{array}$ & 68.6 & 48.6 & 80 & 51.4 & 68.5 & 8.6 & 17.1 \\
\hline \multirow[t]{2}{*}{ Other } & $\begin{array}{l}\text { Number of } \\
\text { Sources }\end{array}$ & 7 & 5 & 7 & 9 & 6 & 4 & 2 \\
\hline & $\begin{array}{l}\% w / i n \\
O C\end{array}$ & 70 & 50 & 70 & 90 & 60 & 40 & 20 \\
\hline
\end{tabular}

Column names: Outside sources (OS), Author listed (AL), Contact information (CI), References (Ref), Publication year (PY), Disclosure of partnerships (DoP), and Funding disclosure (Fun.)

*Note: Technical standard is not included in the calculation of a Composite Technical Quality Score (TQS) 
Figure 1. Exclusion Flow Chart

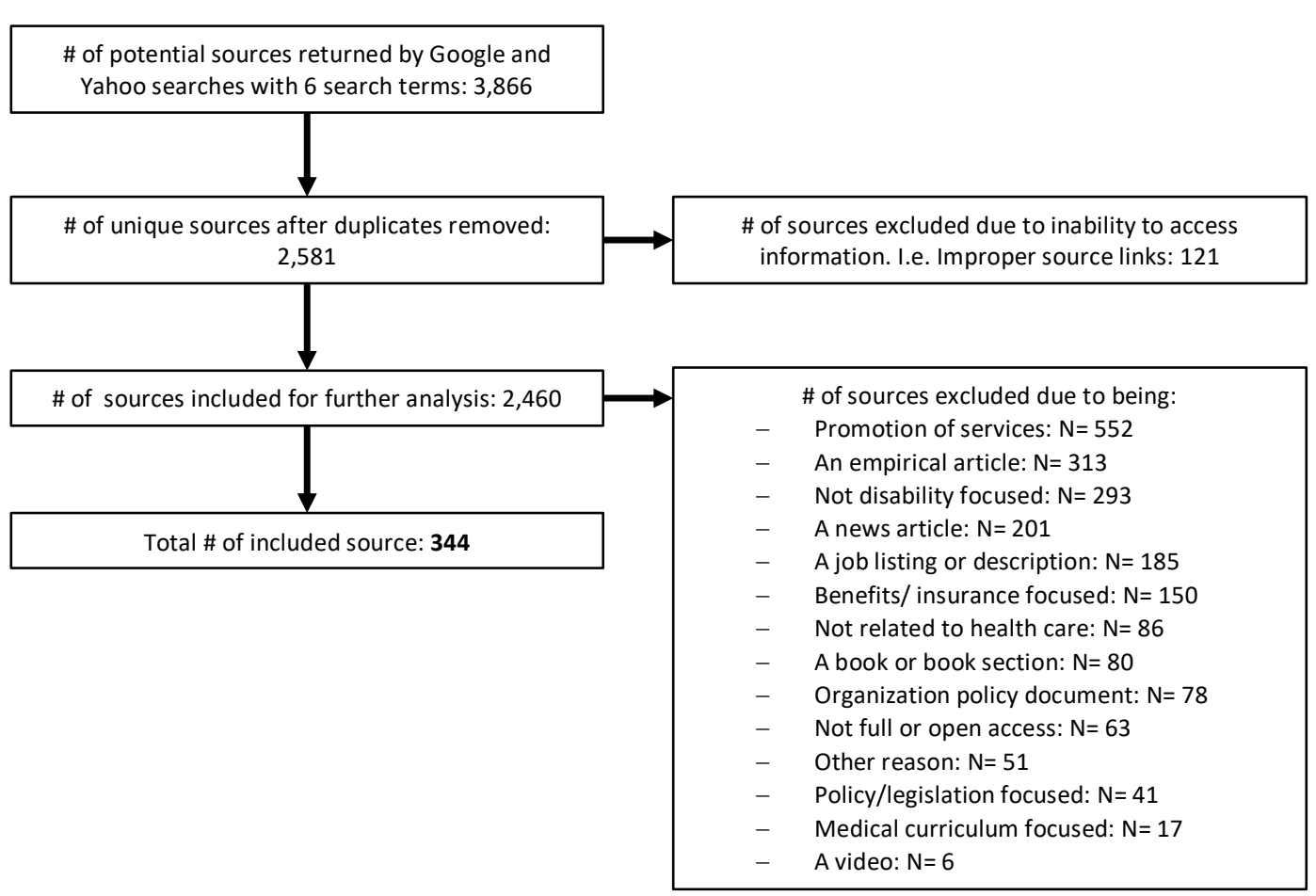




\section{References}

Alsem, M. W., Ausems, F., Verhoef, M., Jongmans, M. J., Meily-Visser, J. M. A., \& Ketelaar, M. (2017). Information seeking by parents of children with physical disabilities: An exploratory qualitative study. Research in Developmental Disabilities, 60(60), 125-134. https://doi.org/10.1016/j.ridd.2016.11.015

Alsem, M. W., Siebes, R. C., Gorter, J. W., Jongmans, M. J., Nijhuis, B. G. J., \& Ketelaar, M. (2014). Assessment of family needs in children with physical disabilities: Development of a family needs inventory. Child: Care, Health and Development, 40(4), 498-506. https://doi.org/10.1111/cch.12093

Bonnar-Kidd, K., Black, D., Mattson, M., Coster, D. (2009). Online Physical Activity Information: Will Typical Users Find Quality Information? Health Communication, 24(2), 165-175. Retrieved from http://dx.doi.org.libezproxy2.syr.edu/10.1080/10410230802676763

Doney, L., Barlow, H., \& West, J. (2005). Use of libraries and electronic information resources by primary care staff: outcomes from a survey. Health Information \& Libraries Journal, 22(3), 182-188. https://doi.org/10.1111/j.1471-1842.2005.00561.x

Fox, S., \& Duggan, M. (2013). Health Online 2013. JANUARY(Vol. 15). Washington, D.C. https://doi.org/http://www.pewinternet.org/2013/01/15/health-online-2013/

Griffin, E., McKenna, K., \& Worrall, L. (2004). Health Reference Center Academic - Document - Stroke education materials on the world wide web: an evaluation of their quality and suitability. Topics in Stroke Rehabilitation, 11(3), 29. Retrieved from http://go.galegroup.com.libezproxy2.syr.edu/ps/i.do?p=HRCA\&u=nysl_ce_syr\&id=GALE $\% 7 \mathrm{CA} 123413262 \& \mathrm{v}=2.1 \& \mathrm{it}=\mathrm{r} \& \mathrm{sid}=$ summon\&authCount $=1$ 
Iezzoni, L. I., \& Long-Bellil, L. M. (2012). Training physicians about caring for persons with disabilities: "Nothing about us without us!'. https://doi.org/10.1016/j.dhjo.2012.03.003 Independence Care System. (2016). A Blueprint for Improving Access to Primary Care for Adults with Physical Disabilities. New York. NY. Retrieved from http://nyshealthfoundation.org/uploads/resources/A_Blueprint_for_Improving_Access_to_P rimary_Care_for_Adults_with_Physical_Disabilities.pdf

Jetha, A., Faulkner, G., Gorczynski, P., Arbour-Nicitopoulos, K., \& Martin Ginis, K. A. (2011). Physical activity and individuals with spinal cord injury: accuracy and quality of information on the Internet. Disability and Health Journal, 4(2), 112-20. https://doi.org/10.1016/j.dhjo.2010.07.001

Kim, P., Eng, T. R., Deering, M. J., \& Maxfield, A. (1999). Published criteria for evaluating health related web sites: review. BMJ (Clinical Research Ed.), 318(7184), 647-9. Retrieved from http://www.ncbi.nlm.nih.gov/pubmed/10066209

Moher, D., Liberati, A., Tetzlaff, J., \& Altman, D. G. (2009). Guidelines and Guidance Preferred Reporting Items for Systematic Reviews and Meta-Analyses: The PRISMA Statement. PLoS Medicine, 6(7), 1-6. Retrieved from http://journals.plos.org/plosmedicine/article/file?id=10.1371/journal.pmed.1000097\&type= printable

Prestin, A., Vieux, S. N., \& Chou, W. S. (2015). Is Online Health Activity Alive and Well or Flatlining? Findings From 10 Years of the Health Information National Trends Survey. Journal of Health Communication, 20(7), 790-798. https://doi.org/10.1080/10810730.2015.1018590

Purcell, K., Brenner, J., \& Rainie, L. (2012). Search Engine Use 2012. Washington, D.C. 
Retrieved from http:/www.pewinternet.org/files/oldmedia/Files/Reports/2012/PIP_Search_Engine_Use_2012.pdf

Schaefer, N. (2015). Disability search tips and resources. Medical Reference Services Quarterly, 34(1), 60-74. https://doi.org/10.1080/02763869.2015.986792

Schilling, L. M., Steiner, J. F., Lundahl, K., \& Anderson, R. J. (2005). Residents' patient-specific clinical questions: opportunities for evidence-based learning. Academic Medicine : Journal of the Association of American Medical Colleges. https://doi.org/80/1/51 [pii]

Schuers, M., Griffon, N., Kerdelhue, G., Foubert, Q., Mercier, A., \& Darmoni, S. J. (2016). Behavior and attitudes of residents and general practitioners in searching for health information: From intention to practice. International Journal of Medical Informatics, 89, 9-14. https://doi.org/10.1016/j.ijmedinf.2016.02.003

Shaw, R. B., Mallory, K. D., Arkell, J., \& Martin Ginis, K. A. (2017). The technical quality of online leisure time physical activity resources for people with physical disabilities. Disability and Health Journal, 10(1), 93-99. https://doi.org/10.1016/j.dhjo.2016.09.002

Silberg, W. M. (1997). Assessing, Controlling, and Assuring the Quality of Medical Information on the Internet. JAMA, 277(15), 1244. https://doi.org/10.1001/jama.1997.03540390074039

Walsh, E. S., Peterson, J. J., \& Judkins, D. Z. (2014). Searching for disability in electronic databases of published literature. Disability and Health Journal, 7(1), 114-118. https://doi.org/10.1016/j.dhjo.2013.10.005

World Health Organization. (2011). WORLD REPORT ON DISABILITY. Retrieved from http://www.who.int/about/

Younger, P. (2010). Internet-based information-seeking behaviour amongst doctors and nurses: A short review of the literature: Review Article. Health Information and Libraries Journal, 
27(1), 2-10. https://doi.org/10.1111/j.1471-1842.2010.00883.x 